\title{
Exploitation of 3D-Microporous Architecture Surface of Titanium Implant as Local Drug Delivery System
}

\author{
Fatma Al-Zhraa Abdel-Rahman ${ }^{1}$, Nadia Badr ${ }^{2, *}$, Eatimad Shoreibah $^{1}$, Monazah Khafagy ${ }^{3}$, Inas $_{\text {Motawea }}{ }^{1}$ \\ ${ }^{1}$ Faculty of Dental Medicine, Al-Azhar University (Girls’ Branch), Egypt \\ ${ }^{2}$ Faculty of Oral \& Dental Medicine, Cairo University, Affiliated to Umm Al-Qura University, Saudi Arabia \\ ${ }^{3}$ Spectroscopy Department-Physics Division, National Research Center (NCR), Egypt
}

Copyright $(2016$ by authors, all rights reserved. Authors agree that this article remains permanently open access under the terms of the Creative Commons Attribution License 4.0 International License

\begin{abstract}
This study aimed to establish local drug delivery system based on $3 \mathrm{D}$ micro porous architecture implants' surfaces. Twenty two Ti- $\% \% \mathrm{Al}-4 \% \mathrm{~V}$ cylindrical root-form implants were divided into two groups according to surface treatment; acid etching and anodization. Firstly, samples' surfaces were characterized by XRD, SEM, AFM and FTIR. Then, each sample was drug loaded by immersion into an antibiotics solution mixture of Ciprofloxacin (CFX) and Metronidazole (Mtz) in concentration of $200 \mathrm{mg} / 100 \mathrm{~mL}$ and $500 \mathrm{mg} / 100 \mathrm{~mL}$; respectively for $24 \mathrm{hrs}$. The amount of released drug traced by UV-Spectroscopy was observed up to 28 days. The antimicrobial activity of the antibiotic mixture was estimated on a group of gram +ve and gram -ve bacteria. Drugs released with an initial burst; afterward, an abrupt decrease with a sustained steady release rate up to 28 days. The anodized samples showed faster rate and greater amount of drug release than the acid etched ones owing to greater density, larger size and more uniformly distributed micro-pores. The antimicrobial activity of CFX-Mtz drugs mixture was slightly higher in anodized group. However, acid etched samples showed significantly sustained antimicrobial activity up to 14 days.
\end{abstract}

Keywords Surface Treatment, Titanium Implants, Anodization, Drug Release, Antimicrobial Activity

\section{Introduction}

The achievement of local drug delivery in significant active quantities directly at bone/implant interface to prevent and/or treat implant infections; peri-implantitis, is one of the challenging issues. In recent years, controlled drug delivery systems have gained remarkable progress particularly with the prompt development in the advanced materials and technology. Many efforts have been devoted to the realization of biomaterials combining controlled drug delivery properties with the features required by tissue engineering. Among these biomaterials, commercially pure titanium and titanium alloys are well known in the biomedical applications as orthopedic implants since the 1970's [1].

A relationship has been established between the surface chemistry, morphology and texture of an implanted material and biological reactions of tissues in contact [2]. The surface modifications improve the biological, chemical and mechanical properties during clinical serviceability [3]. Various types of surface treatments have been attempted to modify Ti implants' surface that include grit blasting or acid-etching [4], plasma spraying, wet chemical sol-gel deposition technique, hydroxyapatite coatings and lately, anodic oxidation significantly improved the hydrophilicity and benefits osseointegration and dental implant therapy [5, $6]$.

The creation of titania layer in a proscribed fashion legitimate potentiality for its exploitation in localized controlled drug delivery [7]. It was evident that titania minute-tubules templates are not only exhibit improved osteoblast cell adhesion and growth but they are also effective against the bacterial infection [8]. Some authors suggested that an antibacterial loaded hydrogel coating may represent a possible option to protect orthopaedic implants from bacterial colonization. An implant disposable antibacterial direct coating consisted of a fully resorbable, biocompatible hydrogel was served as antibacterial and anti-biofilm agents who prevented infection occurrence in an in vitro model of peri-prosthetic infection $(9,10)$. The controlled delivery should administer the requested amount of drug for therapeutic benefits and optimize the drug delivery profile.

The alteration of the implants surface architecture to be susceptible to locally deliver active amounts of loaded drugs in controlled release rate post-operatively is an essential issue to be addressed. Thus; the present study is triple folded: (i) characterization of the titanium implants after their treatment to create a 3-D porous surface. (ii) Loading of treated surface with a model antibiotic commonly used in 
peri-implantitis and tracing of the kinetics of drug release and (iii) the Assessment of the antimicrobial activity of the model antibiotic in simulated body fluid.

\section{Materials and Methods}

A total of twenty two Ti- $6 \% \mathrm{Al}-4 \% \mathrm{~V}$ alloy cylindrical of root-form shape samples $(4 \pm 0.2 \mathrm{~mm}$ in diameter and $10 \pm$ $0.3 \mathrm{~mm}$ in length) were used. They were either acid etched or anodized to create 3-D porous architecture. The materials used in the present study are listed in Table (1).

Table 1. The materials used in this study, their composition and suppliers

\begin{tabular}{|c|c|c|}
\hline Materials & Composition & Supplier \\
\hline Alloy samples & Ti-6\%Al-4\%V & \multirow{3}{*}{$\begin{array}{c}\text { As prepared in Center of } \\
\text { Metallurgic Research and } \\
\text { Development Institute } \\
\text { (CMRDI) }\end{array}$} \\
\hline Etchant & $\begin{array}{c}\text { Mixture of: } 80 \mathrm{ml} / 1 \quad \mathrm{HNO}_{3}, 60 \\
\mathrm{ml} / 1 \quad \mathrm{HF} \& 150 \mathrm{ml} / \mathrm{H}_{2} \mathrm{O}_{2}\end{array}$ & \\
\hline $\begin{array}{l}\text { Anodizing } \\
\text { solution }\end{array}$ & $\begin{array}{c}\text { Mixture of: } 1 \mathrm{M} \text {. wt.\% } \mathrm{HF} \& 1 \\
\text { M. wt.\% } \mathrm{H}_{3} \mathrm{PO}_{4} \\
\text { (aqueous solution of } \mathrm{PH} 1.6 \text { ) }\end{array}$ & \\
\hline Model drugs & $\begin{array}{l}\text { Antibiotic drugs Mixture of } \\
\text { Ciprofloxacine (CFX) in } \\
\text { conc. } 200 \mathrm{mg} / 100 \mathrm{~mL} \text { and } \\
\text { Metronidazole (Mtz) in } \\
\text { conc. } 500 \mathrm{mg} / 100 \mathrm{~mL}\end{array}$ & $\begin{array}{l}\text { Sigmatec and Amriya } \\
\text { pharmaceutical } \\
\text { industries. }\end{array}$ \\
\hline $\begin{array}{c}\text { Hank`s balanced } \\
\text { solution }\end{array}$ & $\begin{array}{c}\mathrm{CaCl}_{2}, \mathrm{NaCl}, \mathrm{KCl}, \mathrm{NaHCO}_{3}, \\
\text { glucose, } \mathrm{NaH}_{2} \mathrm{PO}_{4}, \mathrm{MgCl}_{2} . \\
\mathrm{H}_{2} \mathrm{O}, \mathrm{Na}_{2} \mathrm{HPO}_{4} .2 \mathrm{H}_{2} \mathrm{O} \& \\
\mathrm{MgSO}_{4}\end{array}$ & $\begin{array}{l}\text { Almadi Company for } \\
\text { medical supplies; }\end{array}$ \\
\hline
\end{tabular}

\subsection{Surface Treatment of the Samples}

The Ti-alloy samples were mechanically polished using Emery paper grit 400-1000 to remove macro-level surface defects. Then, they were ultrasonically (Julbo, Labortevhnik Gmbh, Germany) cleaned in ethyl alcohol for 5 minutes, in deionized water for another 5 minutes and dried by air drier (Braun, Germany).

Twenty samples were divided into two groups $(n=10)$ according to the received surface treatment. Group 1 samples were acid etched by immersion in a mixture of $80 \mathrm{ml} / 1 \mathrm{HNO}_{3}$, $60 \mathrm{ml} / 1 \mathrm{HF}$, and $150 \mathrm{ml} / 1 \mathrm{H}_{2} \mathrm{O}_{2}$ for 5 minutes at room temperature. Group 2 samples were potentiostatically anodized in a designed electrochemical cell. A Ti-alloy sample was connected as an anode and a platinum basket served as a cathode with distance $2 \mathrm{~cm}$ apart. The electrolyte was a mixture of $1 \mathrm{M} . \mathrm{wt} \% \mathrm{HF}$ and $1 \mathrm{M} . \mathrm{wt} \% \mathrm{H}_{3} \mathrm{PO}_{4}$ aqueous solution of $\mathrm{pH} 1.6$. A direct current source (Munk Ps $\alpha$ Vari plus $25 \mathrm{~V} / 50 \mathrm{~A}$, Germany) of constant voltage $20 \mathrm{~V}$ was used while stirring with $140 \mathrm{rpm}$ by magnetic stirrer (WiiseStir $^{\mathrm{TM}}$ feedback control digital timer function (MSH-10), Germany). The anodization process was performed for $35 \mathrm{~min}$ at room temperature (11). The samples of both groups were cleaned as previously mentioned. Two samples were kept untreated to serve as control for surface characterization.

\subsection{Surface Characterization}

The treated surfaces of the Ti- $6 \% \mathrm{Al}-4 \% \mathrm{~V}$ alloy samples were characterized by X-ray diffraction method (XRD) to identify the constituents' phases of the sample surface and their average crystal size using thin film X-ray diffractometer (PAN analytical, X'Pert Pro, Holana); Scanning electron microscope (SEM) (JEOL JSM 5410, Japan) to examine surface morphology and Atomic force microscopy (AFM) (Hermomicroscopes Autoprobe CP research, scanner $100 \mathrm{~m}$, USA) to determine the surface micro-roughness and 3D scan imaging of the Ti-alloy samples.

\subsection{Drug loading and in-vitro drug release}

Ciprofloxacin (CFX) antibiotic solution of chemical formula $\left(\mathrm{C}_{17} \mathrm{H}_{18} \mathrm{FN}_{3} \mathrm{O}_{3}\right)$ and molecular weight $331.346 \mathrm{~g} / \mathrm{mol}$ and Metronidazole (Mtz) antibiotic of chemical formula $\left(\mathrm{C}_{6} \mathrm{H}_{9} \mathrm{~N}_{3} \mathrm{O}_{3}\right)$ and molecular weight $171.15 \mathrm{~g} / \mathrm{mol}$ [9-11], were mixed together as an aqueous mixture. The ratio of CFX to Mtz was 2:3 (by wt). The concentrations of CFX and Mtz in this combination were 200 and $500 \mathrm{mg} / 100 \mathrm{~mL}$; respectively. Prior to CFX-Mtz drug loading, FTIR was used to qualify the nature of this combined drug solution either it formed a mixture or compound.

Each group samples were loaded with antibiotics CFX -Mtz by immersing each sample in $20 \mathrm{ml}$ of the prepared mixture solution. Then, a stirring for $2 \mathrm{~h}$ at a constant rate of $70 \mathrm{rpm}$ was performed to augment the drug intake followed by immersion for 24 hours at $37^{\circ} \mathrm{C}$ in sealed vials.

The drug-loaded samples were removed from the solutions and placed separately in sealed plastic vials containing $6 \mathrm{ml}$ of Hank's balanced solution of $\mathrm{pH}$ 7.4. The samples were incubated at $37^{\circ} \mathrm{C}$ under static conditions. The soaking solution was collected according to predetermined immersion time periods; $1,2,3,4,5$, and 6 hours and every 24 hours up to 10 days and then for two, three and four weeks successively. The solution samples were collected by dragging $2 \mathrm{~mL}$ of the soaking medium and then were replaced by an equal volume of fresh Hank's solution. The absorbance of the immersion solutions throughout the selected periods was determined using UV-Visible absorption spectroscopy (V- 560, UV/VIS Spectrophotometer, Japan) to detect the amount of the released drug from the alloy samples.

The characteristic absorption wavelengths corresponding to CFX and Mtz drug mixture were determined and different drug standard solutions were deduced to establish a calibrating curve.

\subsection{Assessment of Anti-microbiological Activity}

A microbiological assay was performed for the collected drug solution samples at $1^{\text {st }}, 7^{\text {th }}, 14^{\text {th }}$ and $21^{\text {th }}$ days. The 
antimicrobial activity of the released amount of Ciprofloxacin and Metronidazol antibiotic mixture during these periods was assessed on a group of gram positive and gram negative bacteria to determine the effective concentration of those drugs.

\subsection{Statistical Analysis}

The data of surface roughness, drug release and antimicrobial activity were tabulated and statistically analyzed using the analysis of variance (ANOVA). A p-value $<0.05$ was considered statistically significant. A correlation was tried to be established between UV quantification of the released drug and the anti-microbial effect to determine the effective (CFX-Mtz) mixture \% that had anti microbiological activity.

\section{Results}

\subsection{Surface Characterization}

\subsubsection{X-ray Diffraction Analysis (XRD)}

XRD pattern of untreated Ti-6Al\%- $4 \mathrm{~V} \%$ alloy sample is shown in table (2) and Figure (1-a). The peak values were compared with ICDD cards number 01-070-0826, 04-0551 and 01-073-1117 corresponding to $\mathrm{TiO}_{2}$ anatase, $\mathrm{TiO}_{2}$ rutile and $\mathrm{Ti}_{3} \mathrm{O}$; respectively. The results revealed that the surface of the sample is formed of those oxides. The maximum peak relative $\mathrm{I} / \mathrm{I}_{\mathrm{o}}$ intensity of $100 \%$ was found at $\mathrm{d}=2.23857$ and $2 \theta=40.2889^{\circ}$ corresponding to anatase $\mathrm{TiO}_{2}$ phase.

XRD pattern of acid etched and anodized Ti-alloy samples are shown table ( $3 \& 4$ ) and Figures (1-b \& 1-c); respectively. The peak values were compared with ICDD cards number 01-070-0826, 04-0551, 01-073-1117, 01-073-1118 and 00-051-0636 corresponding to $\mathrm{TiO}_{2}$ anatase, $\mathrm{TiO}_{2}$ rutile, $\mathrm{Ti}_{3} \mathrm{O}, \mathrm{Ti}_{6} \mathrm{O}$ and $\mathrm{TiO}$; respectively. Similarly, the maximum peak intensity of $100 \%$ was also found at the same position as the control sample $2 \theta=40.5$ of $\mathrm{TiO}_{2}$ anatase phase.

Table 2. X-ray diffraction peak values of control Ti- alloy samples:

\begin{tabular}{|c|c|c|c|c|c|c|c|c|c|}
\hline \multirow{2}{*}{ ICDD } & \multicolumn{7}{|c|}{$\mathrm{Ti} \mathrm{O}_{2}$ (Anatase) } & $\mathrm{Ti} \mathrm{O}_{2}$ (Rutile) & $\mathrm{Ti}_{3} \mathrm{O}$ \\
\hline & \multicolumn{7}{|c|}{ 01-070-0826 } & $04-0551$ & 01-073-1117 \\
\hline $2 \theta$ & 40.3 & 38.6 & 70.9 & 53.0 & 77.8 & 63.3 & 35.28 & 82.52 & 76.65 \\
\hline d- value & 2.24 & 2.33 & 1.33 & 1.73 & 1.23 & 1.47 & 2.54 & 1.17 & 1.24 \\
\hline $\mathrm{I} / \mathrm{I}_{0} \%$ & 100 & 51.1 & 36.6 & 21.0 & 10.1 & 7.79 & 7.55 & 7.97 & 17.05 \\
\hline Crystal size & 25.5 & 25 & 11.1 & 27.4 & 53.3 & 7.9 & 25.5 & 3 & 4 \\
\hline
\end{tabular}

Table 3. X-ray diffraction peak values of acid etched Ti- alloy samples:

\begin{tabular}{|c|c|c|c|c|c|c|c|c|c|c|c|c|c|}
\hline \multirow{3}{*}{$\begin{array}{c}\text { ICDD } \\
2 \theta\end{array}$} & \multicolumn{6}{|c|}{$\mathrm{Ti}_{2}$ (Anatase) } & \multicolumn{2}{|c|}{$\mathrm{Ti} \mathrm{O}_{2}$ (Rutile) } & \multicolumn{2}{|c|}{$\mathrm{TiO}$} & $\mathrm{Ti}_{3} \mathrm{O}$ & \multicolumn{2}{|c|}{$\mathrm{Ti}_{6} \mathrm{O}$} \\
\hline & \multicolumn{6}{|c|}{ 01-070-0826 } & \multicolumn{2}{|c|}{ 04-0551 } & \multicolumn{2}{|c|}{ 00-051-0636 } & 01-073-1117 & \multicolumn{2}{|c|}{ 01-073-1118 } \\
\hline & 40.5 & 38.6 & 71.00 & 35.44 & 63.5 & 53.28 & 78.15 & 82.56 & 39.5 & 57.09 & 74.94 & 76.84 & 87.67 \\
\hline d-value & 2.23 & 2.33 & 1.33 & 2.53 & 1.46 & 1.72 & 1.22 & 1.17 & 2.28 & 1.61 & 1.27 & 1.24 & 1.11 \\
\hline $\mathrm{I} / \mathrm{I}_{0} \%$ & 100 & 80.3 & 29.19 & 24.83 & 22.4 & 18.79 & 13.05 & 5.77 & 10.25 & 2.49 & 3.1 & 21.22 & 2.22 \\
\hline Crystal size & 78.7 & 86.1 & 44 & 57.5 & 57.8 & 97.1 & 40.2 & 3 & 77.3 & 47.3 & 3 & 60.1 & 3 \\
\hline
\end{tabular}

Table 4. X-ray diffraction peak values of anodized Ti- alloy samples:

\begin{tabular}{|c|c|c|c|c|c|c|c|c|c|c|c|c|c|c|}
\hline \multirow{3}{*}{$\begin{array}{c}\text { ICDD } \\
2 \theta\end{array}$} & \multicolumn{5}{|c|}{$\mathrm{Ti} \mathrm{O}_{2}$ (Anatase) } & \multicolumn{2}{|c|}{$\mathrm{Ti}_{3} \mathrm{O}$} & \multicolumn{2}{|c|}{$\mathrm{Ti}_{6} \mathrm{O}$} & \multicolumn{2}{|c|}{$\mathrm{Ti} \mathrm{O}_{2}$ (Rutile) } & \multicolumn{3}{|c|}{$\mathrm{TiO}$} \\
\hline & \multicolumn{5}{|c|}{ 01-070-0826 } & \multicolumn{2}{|c|}{ 01-073-1117 } & \multicolumn{2}{|c|}{ 01-073-1118 } & \multicolumn{2}{|c|}{ 04-0551 } & \multicolumn{3}{|c|}{ 00-051-0636 } \\
\hline & 40.5 & 70.99 & 53.3 & 38.6 & 35.5 & 63.7 & 74.9 & 76.83 & 87.5 & 78.14 & 82.57 & 71.86 & 39.61 & 57.24 \\
\hline d- value & 2.23 & 1.33 & 1.72 & 2.33 & 2.5 & 1.46 & 1.27 & 1.24 & 1.11 & 1.22 & 1.17 & 1.31 & 2.27 & 1.61 \\
\hline $\mathrm{I} / \mathrm{I}_{0} \%$ & 100 & 82.25 & 38.9 & 22.8 & 17.3 & 95.9 & 7.44 & 52.44 & 9.27 & 38.53 & 14.20 & 10.61 & 8.03 & 7.53 \\
\hline Crystal size & 73.1 & 46.9 & 99.8 & 69.9 & 42.4 & 62.2 & 42 & 46.4 & 3 & 45 & 3 & 3 & 106.3 & 81.6 \\
\hline
\end{tabular}




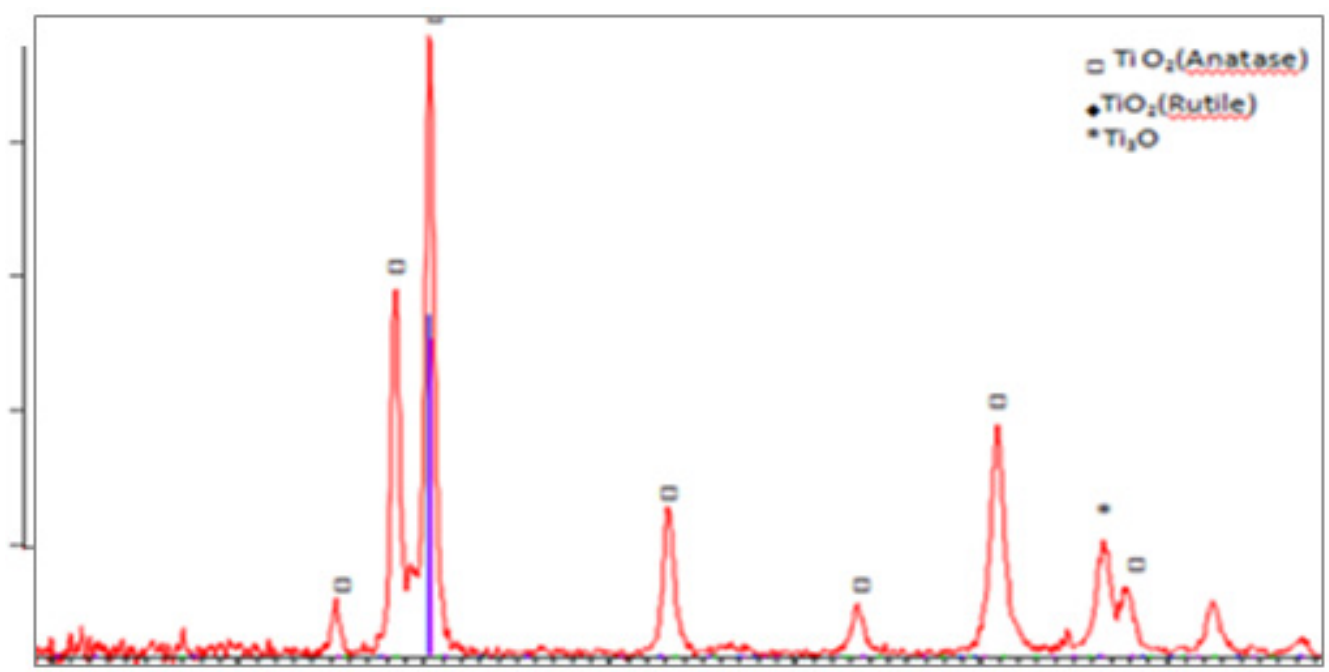

a

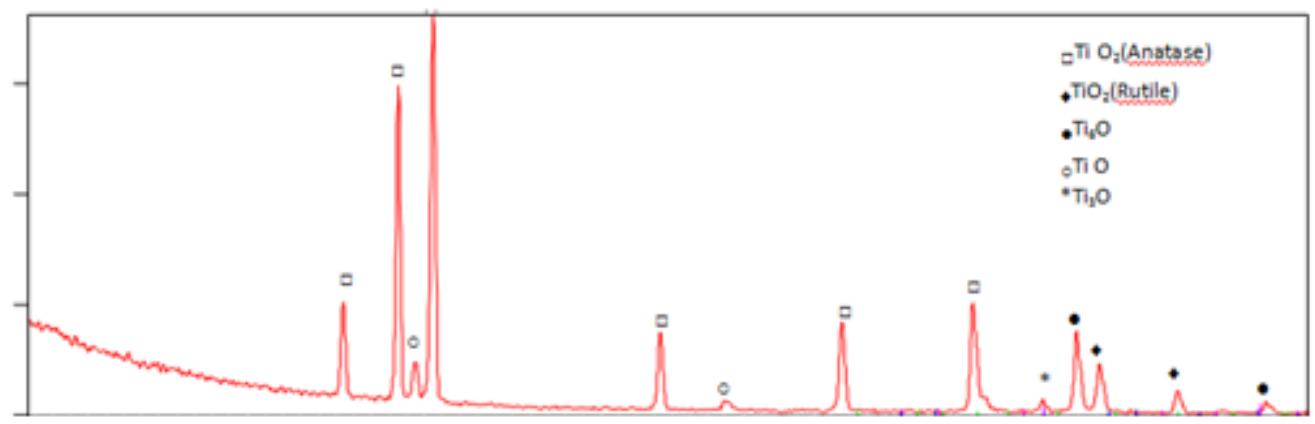

b

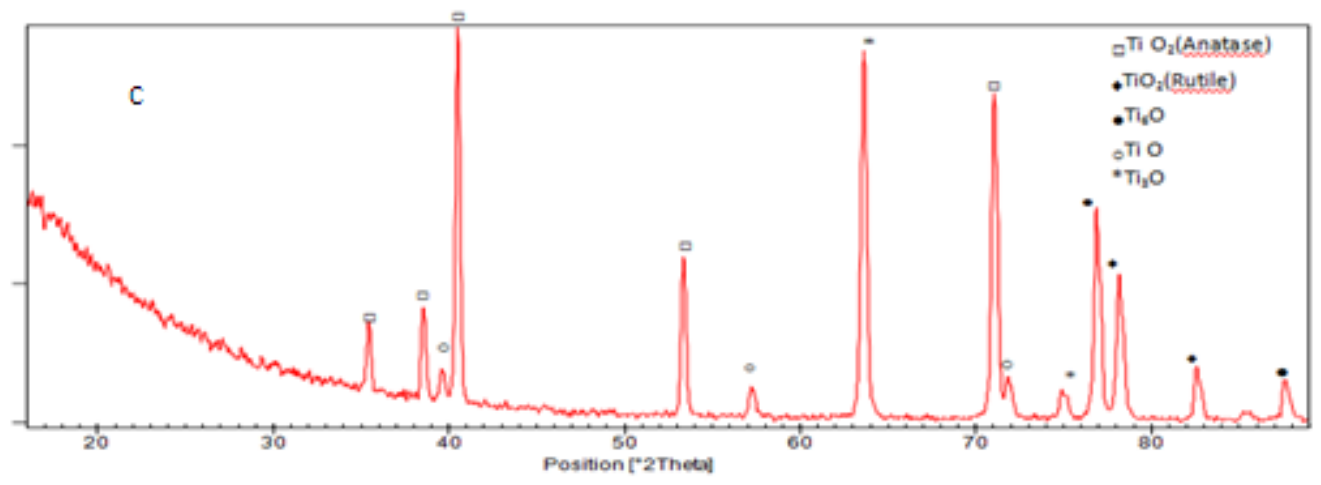

c

Figure 1. XRD patterns of Ti-alloy samples: control (a), acid etched (b), anodized (c) 


\subsubsection{SEM Examination and 3D AFM Scanning Image}

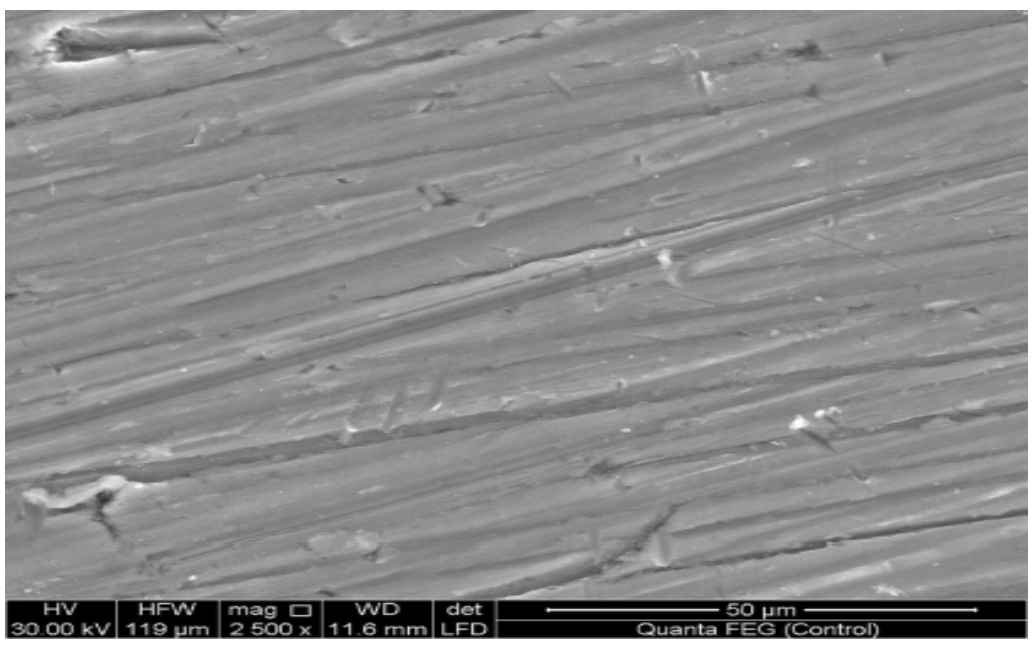

Figure 2-a. SE Micrograph of control Ti-alloy at X2500 reveals shallow grooves and scratches. Smooth parallel straie are present due to mechanical polishing which removed scratch marks originally made during machining of the specimen. There are also few discrete pores through the specimen surface with irregular and variant diameters.

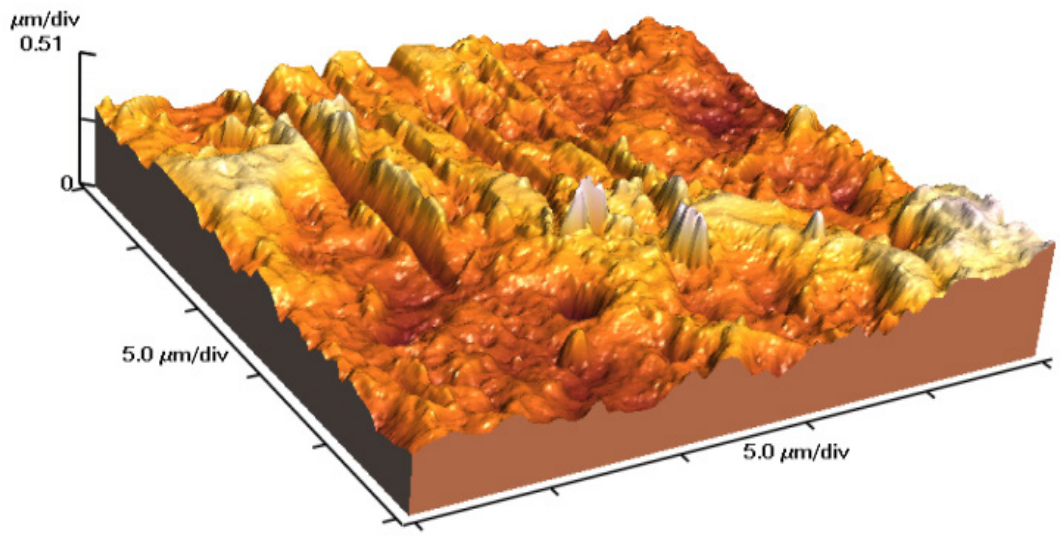

Figure 2-b. AFM 3D scanning image of the control sample reveals inhomogeneous surface texture denoting parallel straie lines having sharp peaks.

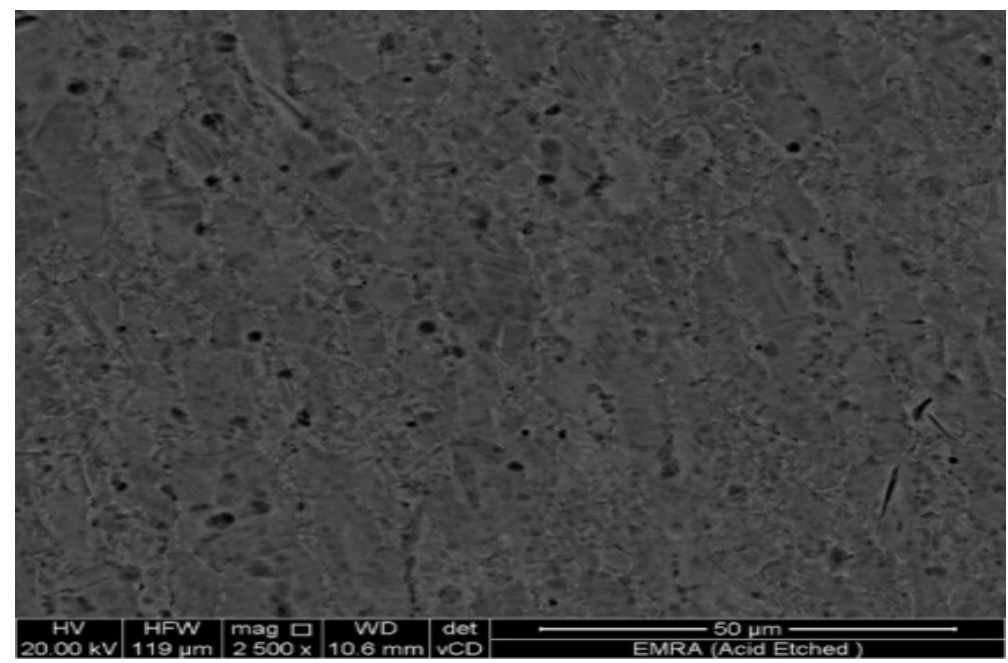

Figure 3-a. SE Micrographs of acid etched Ti-alloy X2500. The surface morphology shows the disappearance of the straie. There are multiple, scattered and disorderly arranged micropores. The pores diameters range from 1.1 to $2.1 \mu \mathrm{m}$. 


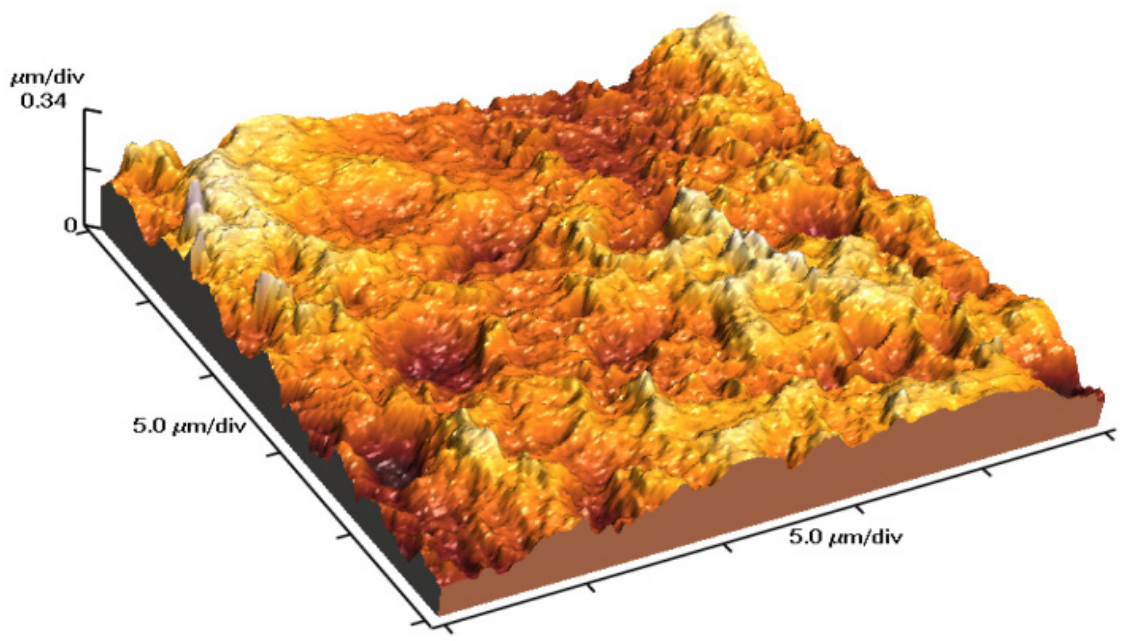

Figure 3-b. AFM 3D scanning image of the acid etched sample shows more uniform surface texture with more rounded peaks' edges and shallow valleys.

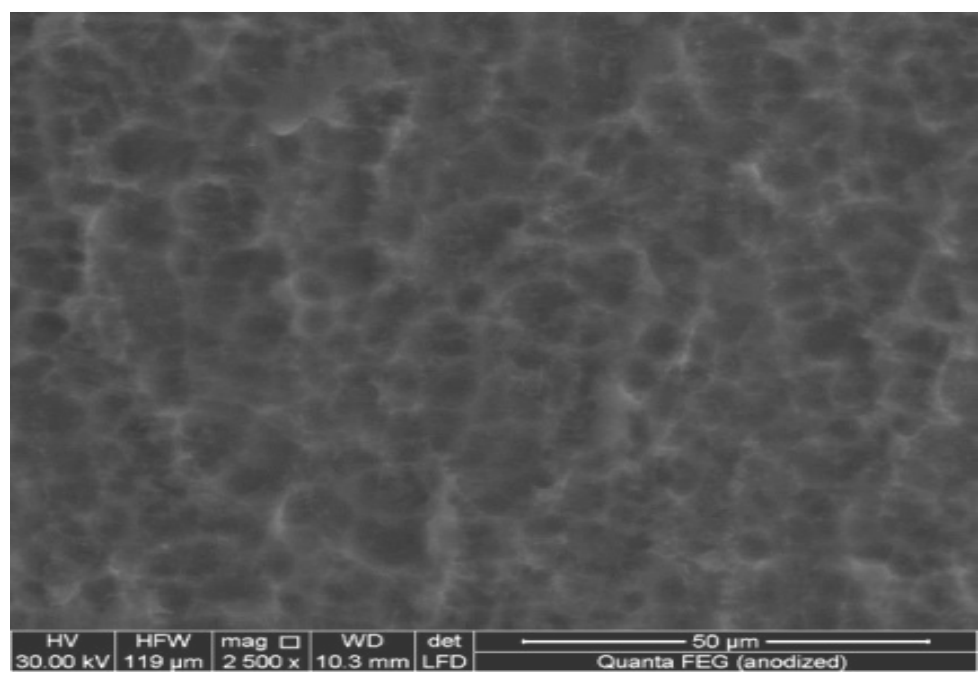

Figure 4-a. SE Micrographs of anodized Ti-alloy at X2500. The surface morphology of the sample is characterized by the presence of multiple, and well-orderly arranged micropores in nearly uniform distribution resembling the microscopic picture of spongy structure. The pores diameters ranged from 2.8 to $4.3 \mu \mathrm{m}$.

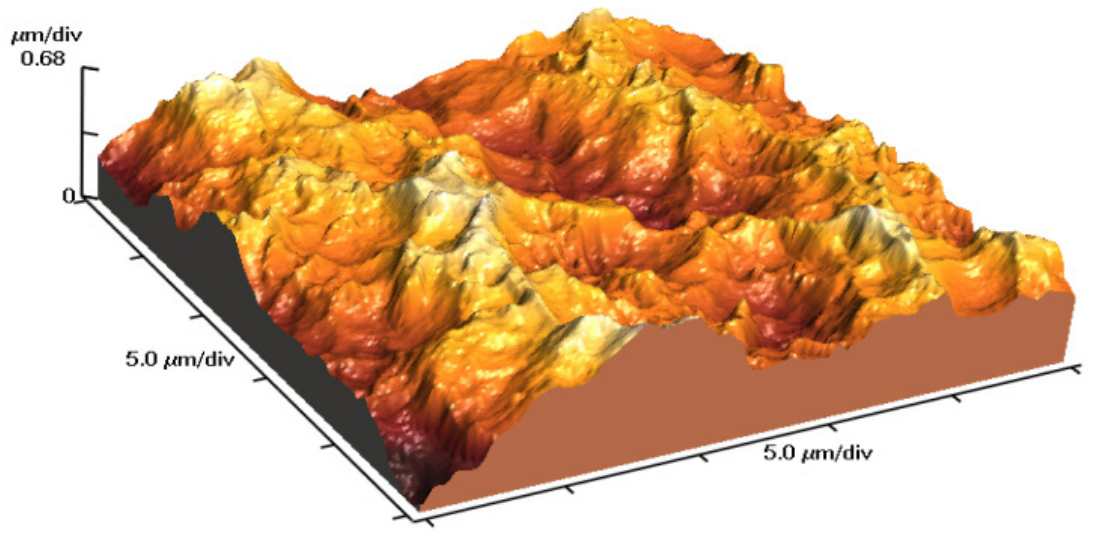

Figure 4-b. AFM 3D scanning image of the anodized group exhibits irregular rough surface texture of marked prominent peaks and deep broad valleys.

\subsubsection{Surface Roughness}

The statistical analysis of the surface roughness data revealed that there was non-significant difference between the control and the acid etched groups in all parameters at

$\mathrm{P} \leq 0.05$. However, both groups had roughness values significantly lower than the anodized sample for the same parameters. 
The values are listed in table (5).

Table 5. The descriptive statistical analysis of surface roughness data of the investigated groups:

\begin{tabular}{|c|c|c|c|c|}
\hline Group & Ra $(\mathrm{nm})$ & Rp-v $(\mathrm{nm})$ & Rq rms $(\mathrm{nm})$ & surface $\operatorname{area}\left(\mu \mathrm{m}^{2}\right)$ \\
\hline Control & $80.84^{\mathrm{a}} \pm 6.29$ & $834.25^{\mathrm{a}} \pm 182.75$ & $101.04^{\mathrm{a}} \pm 7.66$ & $635.70^{\mathrm{a}} \pm 4.50$ \\
\hline Etched sample & $69.93^{\mathrm{a}} \pm 10.47$ & $688.67^{\mathrm{a}} \pm 8.41$ & $88.19^{\mathrm{a}} \pm 10.54$ & $635.80^{\mathrm{a}} \pm 0.85$ \\
\hline Anodized sample & $126.99^{\mathrm{b}} \pm 28.41$ & $1389.33^{\mathrm{b}} \pm 127.93$ & $162.07^{\mathrm{b}} \pm 32.60$ & $651.85^{\mathrm{b}} \pm 2.39$ \\
\hline P value & 0.0171 & 0.0013 & 0.0091 & 0.0008 \\
\hline
\end{tabular}

* P-value $<0.05$ was considered statistically significant.

* Mean values marked with different letters in the same column are significantly different.

\subsection{In vitro Drug Release Measurement}

The amount of CFX-Mtz released from both acids etched and anodized samples throughout the predetermined periods are shown in figures $(5 \& 6)$.

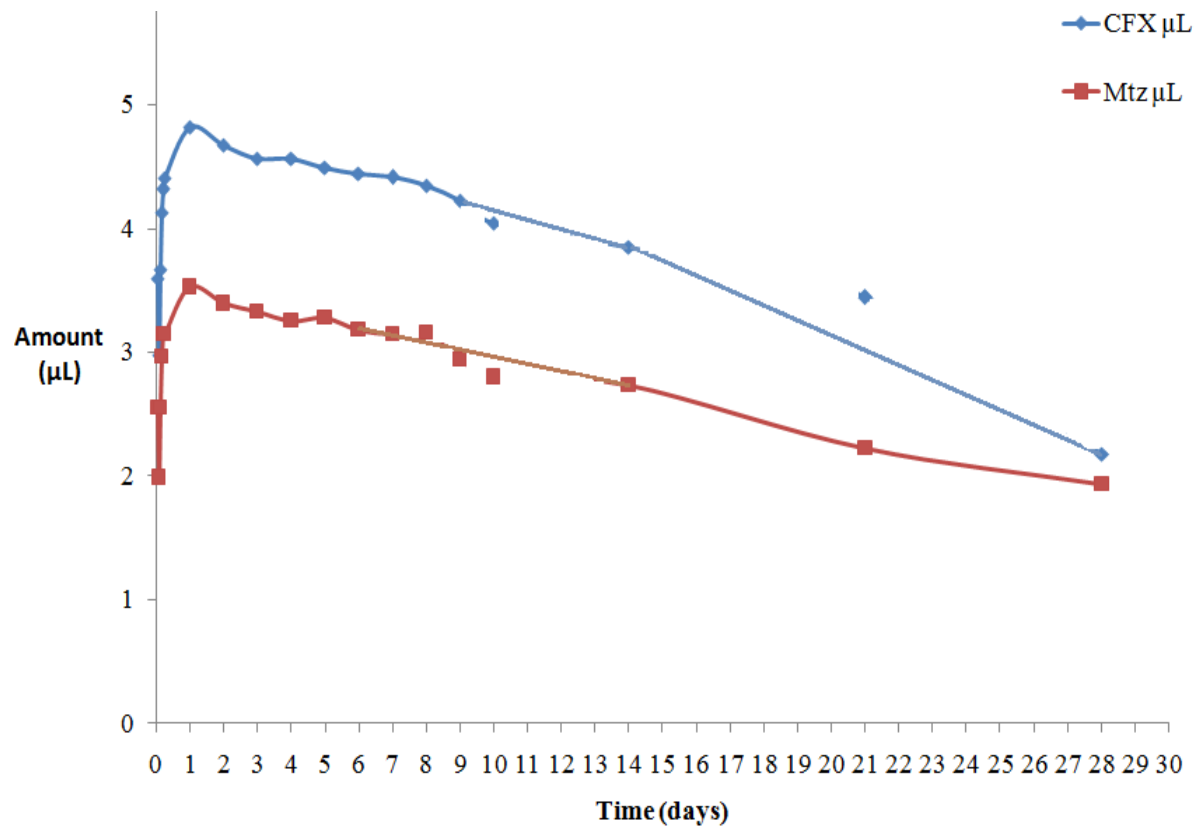

Figure 5. The amount of CFX-Mtz drug mixture released from acid etched samples over 28 days

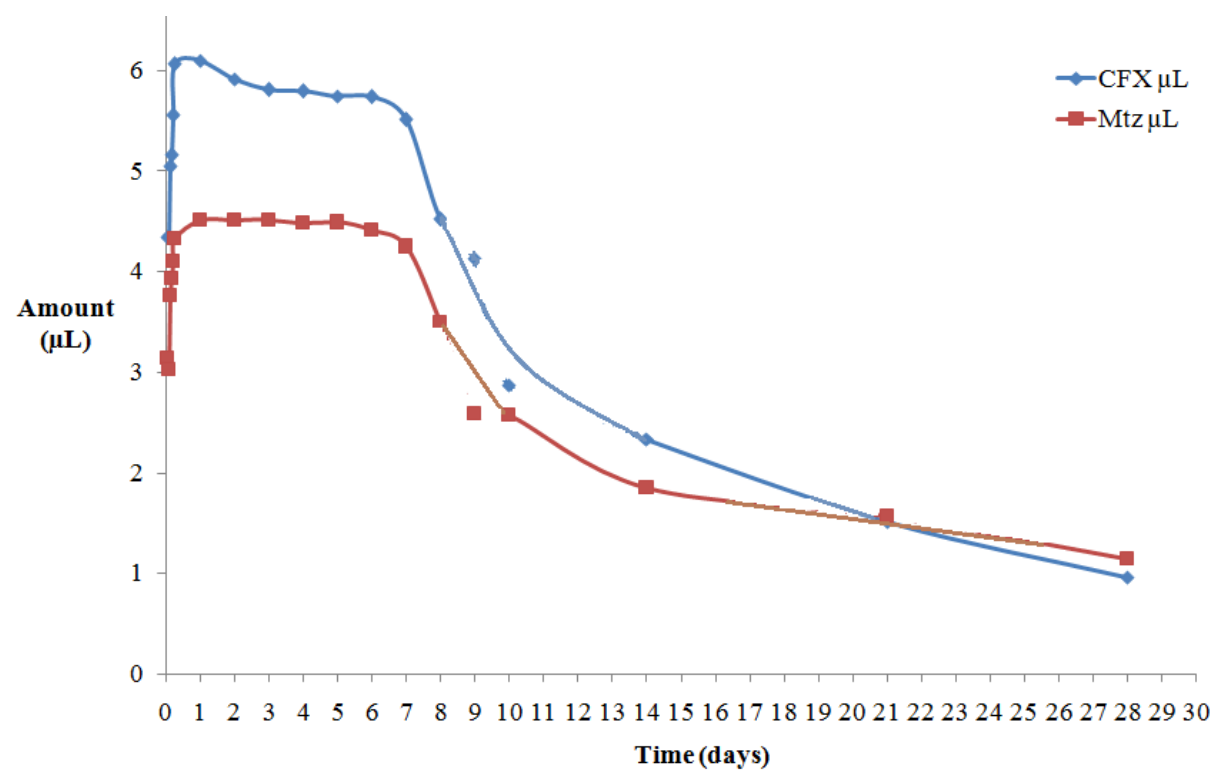

Figure 6. The amount of CFX-Mtz drug mixture released from anodized samples over 28 days 


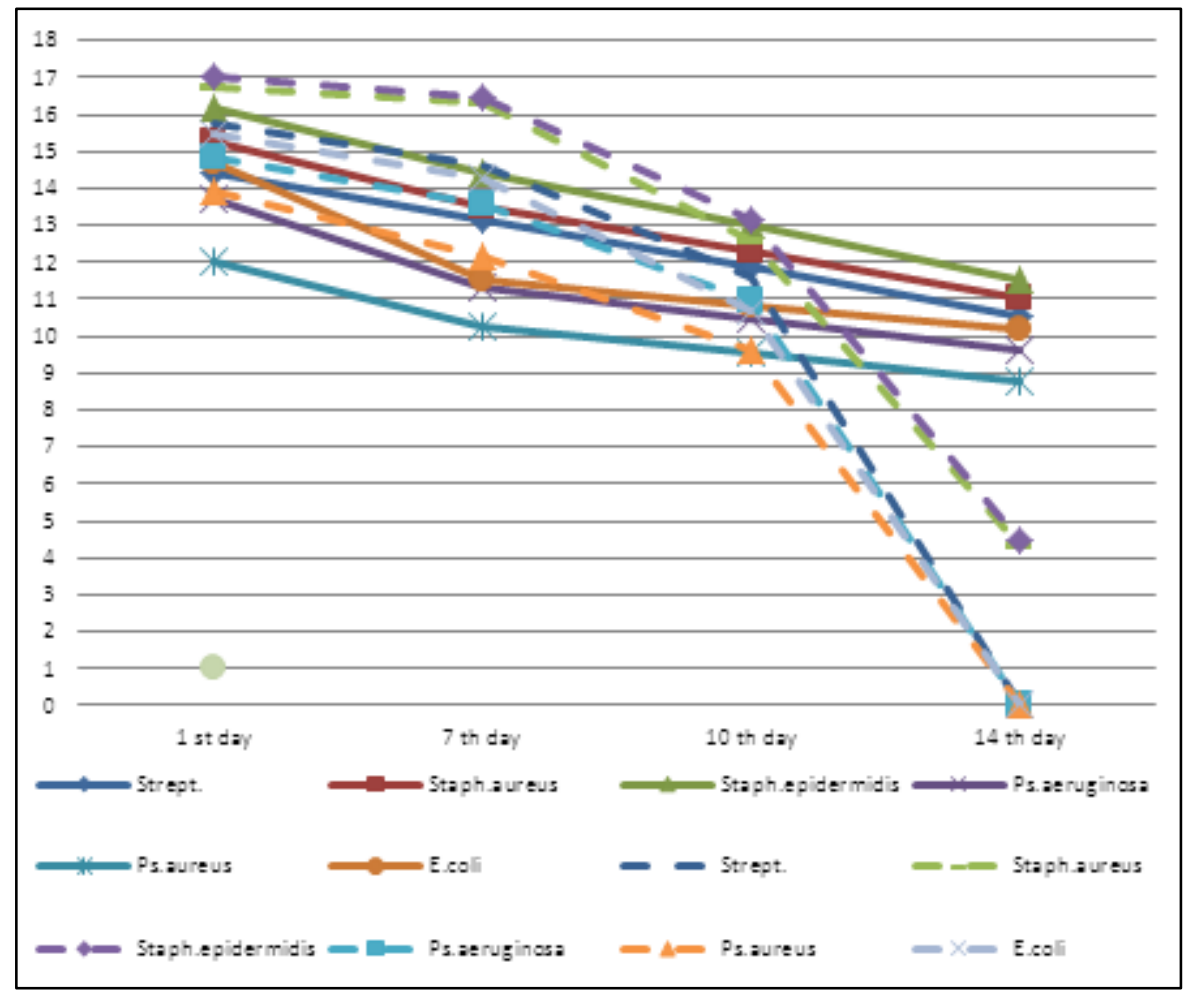

Figure 7. Curves showing the antimicrobial activity of CFX-Mtz drug mixture released from acid etched (solid line) and anodized (dotted line) samples

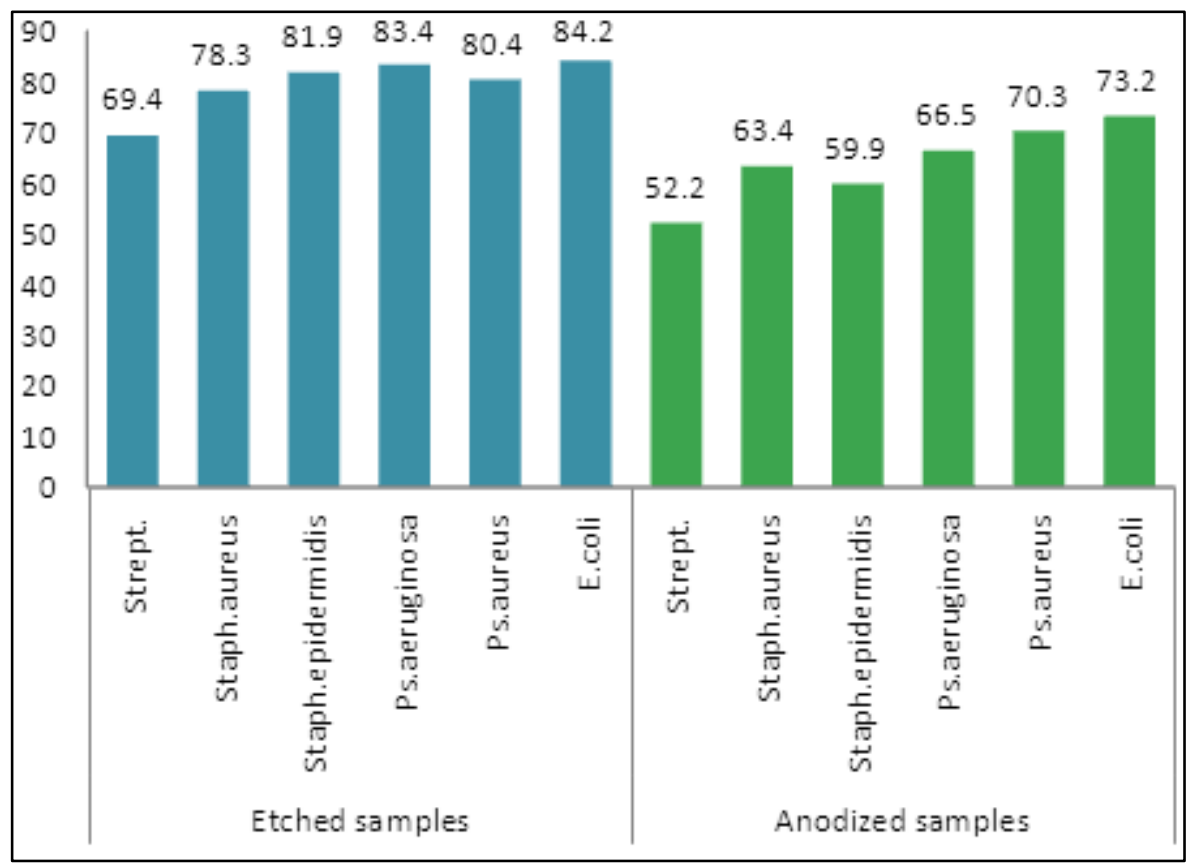

Figure 8. A histogram showing a relationship between the amounts of released drug and the antimicrobial activity throughout the time intervals

\subsection{Assessment of Anti-microbiological Activity}

The anti-microbiological activity test was carried out on a range of environmental and clinically pathogenic microorganisms which were Gram +ve bacteria namely Streptococci, Staphylococcus aureus and Staphylococcus Epidermidis and Gram-ve bacteria, namely E.coli, Pseudomonas aeruginosa and Pseudomonas aureus.

The statistical analysis revealed that the inhibition zone diameter was always larger for the anodized group; however, there was non-significant difference at $\mathrm{P}<0.05$ between the antimicrobial activities of the acid etched and those of anodized samples at any time interval.

The antimicrobial effect of acid etched samples up 14 days was continued with comparable non-significant activity. It was detected that the significant drop of the antimicrobial effect was at the $21^{\text {th }}$ day. Meanwhile, the anodized sample 
remained insignificantly effective up to the $7^{\text {th }}$ day and then fall significantly, as shown in Figure (7).

Generally, a statistical direct correlation could be established between UV quantification of the released CFX-Mtz drug mixture and their anti-microbiological activity. Figure (8) exhibits the \% of antimicrobial activity that is affected by the change in the amount of drug released throughout the time intervals. In the acid etched samples, it was observed that the percentage of the antimicrobial activity affected by the amount of released drug was higher than that of the anodized samples.

\section{Discussion}

Ti - alloys have driven a lot of interest for load bearing implants due to higher mechanical properties, low density, and excellent biocompatibility under in vivo conditions [1]. Upon exposure to oxygen, titanium develops a layer of titanium oxide; titania, with a few nanometers thickness on its surface which is responsible for their superior properties $[4,12]$.

\subsection{Surface Treatment of the Samples}

The topography of implant surface is decisive for determining the integrity at implant/ tissue interface [13]. $\mathrm{Ti}-6 \% \mathrm{Al}-4 \% \mathrm{~V}$ alloy samples were etched or anodized to create rough and porous surfaces. It was proved that the implants' porosity and surface roughness aid in cell adhesion, proliferation and differentiation allowing for better osseointegration [8, 14,15]. Moreover, the porosity could provide vessels for drug loading with consequent release $[16,17]$. The possibility to tune the pore size, distribution and density of the substrate allows a better control of the drug release profile. A carrier porous material is characterized by large surface area and considerable pore volume that are fundamental to ensure the loading of the substrate with the desired amount of drug, thus increasing its adsorption capacity [18]. The tuneable pores size dimension hardly affects the performance of a drug delivery system, because it influences the rate by which the drug is released from the matrix. [19].

\subsubsection{Acid etching of the samples}

Group 1, Ti-alloy samples were etched with a mixture of strong $\mathrm{HNO}_{3}$, $\mathrm{HF}$ acids and $\mathrm{H}_{2} \mathrm{O}_{2}$ that were used in previous studies as a method for roughening Ti-alloy implants [20,21]. At the same time, acid etching produced micro porous surfaces needed for drug loading of the implant samples. The nitric acid helps in passivation of Ti- alloy, decreasing the metal ion release and also improves the surface properties influencing the cell proliferation and alkaline phosphatase activity of osteoblasts [22]. HF would allow the formation of soluble $\mathrm{TiF}_{4}$ species due to high reactivity of Titanium to fluorine ions that are favorable to the osseointegration of dental implants $[21,23,24]$. Meanwhile, $\mathrm{H}_{2} \mathrm{O}_{2}$ is an oxidizing agent allows oxide growth at the surface of metal due to interaction of the metal with $\mathrm{O}^{-2}$ or $\mathrm{OH}^{-}$ions that alters the stoichiometry of oxides to be more beneficial for osseointegration.

The native protective oxide film generally encapsulating Titanium and Ti alloys is composed of three different layers, $\mathrm{TiO}$ (inner layer in contact with the metal), $\mathrm{Ti}_{2} \mathrm{O}_{3}$ (intermediate layer), and $\mathrm{TiO}_{2}$ (outer layer). When titanium is immersed in an oxidizing solution, the suboxides, TiO, and $\mathrm{Ti}_{2} \mathrm{O}_{3}$ are transformed into $\mathrm{TiO}_{2}$ in the oxidizing medium while the etching solution penetrates the micro-pits and reaches the underlying metal. Hence, passivation layers are naturally created and the native layered structure is reestablished [20].

It should be pointed out that the roughness of the acid etched group was not significantly different from control group, acid etching resulted in the presence of micropores; table (5) and figure (2-a and 3-a).

\subsubsection{Anodization of the samples}

Group 2, Ti-alloy samples were subjected to simple and economical electrochemical surface treatment; anodization. Following acid etching, a potentiostatic electric anodization of the samples' surfaces in a mixture of $\mathrm{HF}$ and $\mathrm{H}_{3} \mathrm{PO}_{4}$ was performed. $\mathrm{H}_{3} \mathrm{PO}_{4}$ allows the formation of more porous oxide layer and also provides phosphate ions that can be incorporated into the anodic titania to stimulate the formation of the bio-compatible hydroxyapatite [25].

$\mathrm{TiO}_{2}$ ordered arrays were formed on the titanium substrates in tubular structure by anodization which is useful for drug delivery. These layers can be adjusted in diameter by controlling the applied voltage and in length by controlling anodization time, potential, $\mathrm{pH}[7,17]$ as well as the type of the electrolyte [26].

The current densities start to increase in the next stage and pores start to grow randomly. There is a contest between the growing pores and the current densities until a stable, ordered pore growth has been established. Stresses exist due to the oxides volume change accompanying the oxidation of titanium and presence of various crystalline state resulted in selective dissolution. The initially formed pores are irregular due to non-uniform corrosion. Speed of dissolution and oxidization is different in pores of different diameters. Along with the anodization, the pores' diameters turn to be more uniform. The thickness of the oxide film is thicker at the wall of the pore than at the bottom. Consequently, the electrical field intensity at the pore bottom is much higher than that at the wall. Titania would be consumed at higher rate near the bottom of the pore, which results in further pore growth toward the Ti substrate i.e. increase in depth [27].

\subsection{Surface Characterization}

It has been reported that in the case of the anodization of Ti-alloys, the oxide exhibits a phase transition with increasing potential into crystalline phases such as anatase or rutile [27]. In the present study, XRD patterns indicated 
that the predominant phase in all sample groups; including the control one, was $\mathrm{TiO}_{2}$ (anatase) phase besides $\mathrm{Ti} \mathrm{O}_{2}$ (rutile) and $\mathrm{Ti}_{3} \mathrm{O}$. There was no phase transition had occurred; instead, new oxide phases were appeared; $\mathrm{TiO}$ and $\mathrm{Ti}_{6} \mathrm{O}$, after surface treatment. The anatase phase is much more useful for bone growth than other phases presumably because of better lattice structure that matches with the bone minerals; hydroxyapatite (HA), and small crystal size. This phase has the highest chemisorptions capacity due to its higher surface energy, rough surface, and unsaturated oxygen bond [11]. $\mathrm{TiO}_{2}$ layer reduces the direct contact between bone tissue and metals and diminishes the leaching of toxic metal ions especially aluminum and vanadium. As well, it improves hydrophilicity thus stimulates the formation of hydroxyapatite when soaked in simulated body fluid solution and consequently progresses bone osseointegration [28].

SEM examination reveals the surface morphology of the samples. The surface of the control group was smooth with parallel straie due to careful polishing; Figure (2-a). The mechanical polishing removed scratch marks originated during machining of the sample. There are also few discrete pores through the sample surface with irregular and variant diameters contributed to defects in casting procedure. Figure (3-a \& 4a) indicated that the intrinsic oxide layer was dissolved in different areas in the surface treated groups under the attack of the etchant and the anodizing solutions. The dissolution takes place selectively giving multiple micropores. The micropores were uniformly distributed and orderly arranged in anodized group rather than in the acid etched one. This microporous surface layer is beneficial in loading and release of the model drugs. The pores diameter ranged from 1.1 to $2.1 \mu \mathrm{m}$ in acid etched samples. Similarly, Le Guéhennec et al, 2007 [21] produced micro porous titanium surfaces by acid etching procedure with pore sizes ranging from 0.5 to $2 \mu \mathrm{m}$. As well, the anodization process in this study produced micro-pores but with larger diameter that ranged from 2.8 to $4.3 \mu \mathrm{m}$ and length of 127.8 to $242 \mu \mathrm{m}$. Shalaby et al in 2011 [11] fabricated titania nano-tubes array via anodization of Ti-alloys in an anodizing solution consisted of $\mathrm{HF}$ and $\mathrm{H}_{3} \mathrm{PO}_{4}$. They produced nano titania with diameter ranged from 45-60 $\mathrm{nm}$. These discrepancies with their results might be attributed to the different experimental conditions.

AFM allows the visualization of sub-micron or even atomic scale surface structural features. The tapping mode was chosen for the determination of thin metal layers to minimize damage to the sample surface [29]. In Table (5), the control Ti-alloy samples displayed surface morphology with an average surface roughness $(\mathrm{Ra}=80.84 \mathrm{~nm})$. Meanwhile, the acid etched Ti-alloy samples showed relatively insignificant surface roughness value $(\mathrm{Ra}=69.93$ $\mathrm{nm})$. The etchant altered the morphology of samples' surfaces to be smoother, uniformly shorter and less sharpened peaks; (Figure 3-b). The anodized group revealed the highest significant mean surface roughness value $(\mathrm{Ra}=126.99 \mathrm{~nm})$ which was nearly double that of the acid etched one. The parallel straie due to mechanical polishing of the control samples; (Figure 2-b), disappeared due to different surface treatment, however, the anodization led to more uniform surface texture but with marked peaks and deep broad valleys (Figure 4-b).

\subsection{Drug selection}

Based upon the spectrum of combined CFX-Mtz antibiotic solution, the characteristic bands of each drug appeared individually in the spectrum indicating a mixture was formed. CFX-Mtz antibiotic mixture was selected as a model drug because of low molecular weight 331.346 and $171.15 \mathrm{~g} / \mathrm{mol}$ respectively. The micro diameter of pores would facilitate the diffusion of low molecular weight molecules. Moreover, both antibiotics were water soluble to be homogenously mixed with Hank's solution.

Conaz (Norfloxacin-Tinidazole) drug is an effective drug commonly used for treatment of peri-implantitis. It is composed of $400 \mathrm{mg}$ Norfloxacin broad specrum antibiotic that is active against Gram +ve and Gram -ve bacteria and $600 \mathrm{mg}$ Tinidazole which is an active anti-parasitic drug used against protozoal infections and anaerobic bacterial infections where norfloxacin is inactive $[9,10]$.

Similarly, the selected model drug mixture is prepared of Ciprofloxacin (CFX) and Metronidazole (Mtz) in a ratio of 2:3 (by wt); similar to that of Conaz drug. Ciprofloxacin (CFX) antibiotic is the most widely used drug for treatment of bacterial bone infection with a low minimal inhibitory concentration MIC $(0.25-2 \mathrm{mg} / \mathrm{mL})[30,31]$. It is a broad-spectrum antibiotic active against both Gram-positive and Gram-negative bacteria [32]. On the other hand, Metronidazole (Mtz) (Flagyl, and others) is a medication used particularly for anaerobic bacteria and protozoa. Metronidazole is an antibiotic, amebicide, and antiprotozoal, strongly effective against gram -ve bacteria with MIC of $0.032 \mathrm{mg} / \mathrm{mL}$ [33].

\subsection{Drug Loading and Release}

Drug loading for the porous Ti-alloy samples generally is performed through capillary action by immersing the samples in the concentrated drug solution [34]. The use of Hanks' solution as simulating body fluids dissolution medium allows imitation of the behavior in vivo.

In vitro, the most common method to measure the release assays is collecting aliquots from the release medium periodically and replacing it with fresh solution. In vivo, the released drug is likely to be gradually taken up by surrounding cells or gradually transported away from the implant [35]. Thus, only $2 \mathrm{cc}$ was dragged from the $6 \mathrm{cc}$ immersion solution and replaced by $2 \mathrm{cc}$ fresh Hanks' solution to simulate the wash-out effect in body fluids.

The release of drugs is controlled by their chemical nature, i.e., acidic or basic, molecular size, and the diffusion rate into release medium [36]. Additionally, the surface modifications are influential on the release of the drug 
molecules. The pore size is extremely important especially when it becomes comparable with the size of the drug molecule since the diffusion rate becomes pore size dependent; a phenomenon referred to as hindered or restricted diffusion [7]. Generally, the results indicated that the amount of loaded and released drugs and the release rate from anodized samples was greater than those released from acid etched ones. This could be attributed to greater pore volume (diameter and length) of the anodized surface; Table (5). Moreover, higher density of pores/surface area and uniform distribution; Table (5) \& Figure (4-a) indicated that the higher surface roughness of the anodized samples was also able to retain considerable amounts of drug mixture.

During the early release, drug molecules located at the openings of micro pores and adsorbed on the external surface were quickly released, which made the initial burst release. Later, the release of the drug entrapped into the micro pores was dominated by diffusion and the release behavior of these drug molecules. At the last period of drug release, the release rate was controlled by the equilibrium between drug concentration inside the pores and that in the diffusion medium, which resulted in a decline of the release rate [37]; Figure (5 and 6.)

\subsection{The Release of CFX-Mtz Drug Mixture}

The therapeutic basis of the delivery system proposed the release of an effective dose of an appropriate antibiotic. The antibiotic dose must remain above the MIC and below the minimum toxicity concentration (MTC) throughout the release period.

In the present study, the least concentrations of released CFX observed at the $28^{\text {th }}$ day were $4.2 \mu \mathrm{g} / \mu \mathrm{L}(=2.2 \mu \mathrm{L})$ and $1.8 \mu \mathrm{g} / \mu \mathrm{L}(=0.96 \mu \mathrm{L})$ corresponding to the acid etched and anodized Ti-alloy samples, respectively. Those concentrations were higher than the MIC of CFX drug.

The total amount of drugs mixture released from the anodized samples was $508.6 \mu \mathrm{g}$ which was higher than 430.8 $\mu \mathrm{g}$ released from the acid etched ones. This could be attributed to the higher density and larger diameter of pores of anodized samples.

Figures (5 and 6) showed the release profile of CFX-Mtz mixture from loaded acid etched and anodized Ti-alloy samples. The analysis of the CFX-Mtz drug mixture release profile from Ti-alloy samples suggested that the main regulating delivery mechanism is diffusion. At longer times, a monotonic decrease of drug delivery suggested that the release process is affected by balancing effects. Drug release from the implants is likely to be controlled by the penetration of the release medium into the system and diffusion of the drug through the release medium -filled pores of the implant samples [35].

Clearly, the amount of drug released from the implants increased at early time, leading to further diffusion. On time progressing, the release rate decreased indicating depletion of the drug content in the pores of the Ti- alloy samples.
These results indicate that drugs were continuously released from the Ti- alloy samples and transported by diffusion across concentration gradients.

\subsection{Anti-microbiological Activity Assessment}

The long-term antibacterial activity is especially meaningful for implants because of the constant risk of bacterial infection. It was found that the highest value for the investigated groups was observed at the $1^{\text {st }}$ day due to the initial burst release $[9,10]$.

Logically, the normal reduction in the effectiveness of the released drugs by time is conjugated with the significant reduction in the amount of the released drugs at the $21^{\text {th }}$ and $10^{\text {th }}$ days for acid etched and anodized samples respectively Figure $(5 \& 6)$ which is partially responsible for the significant drop in the antimicrobial activity of the investigated groups at the corresponding time; Figure (7). Figure (8) showed the antimicrobial assay at different selected intervals and the percentage of the antimicrobial activity affected by the amount of released drug; respectively. Obviously, the acid etched group exhibited longer-lasting effectiveness despite the inhibition zone diameter was always insignificantly smaller for this group at any time interval. As well, antimicrobial activity percentage in acid etched group was higher than that of the anodized samples. This would referred to the smaller pores diameter of the acid etched group (1.1-2.1 $\mu \mathrm{m})$ compared to anodized group (2.8 to $4.3 \mu \mathrm{m}$ ) granted the release of small but effective amount of antibiotics for longer time.

\section{Conclusions}

1. Altering the surface treatment of titanium implant can produce different surface oxides, microstructures and surface textures that allow the use of this architecture 3D-microporous surface as a local drug delivery device efficiently.

2. The type of surface treatment played an important role on the drug loading and significantly affected the apparent drug release kinetics by controlling the density and size of the micropores. There is a direct proportionality between pore size, density and distribution and the amount of drug released.

3. The anodization process used in this study produced wider, denser and more uniformly distributed micropores; consequently, higher amount of released drug than that of the acid etched ones; however, the later proved a longer term of antimicrobial activity.

\section{REFERENCES}

[1] Paital SR and Dahotre NB. Calcium phosphate coatings for bio-implant applications: Materials, performance factors, and 
methodologies. Materials Science and Engineering, 66 (1): $1-70 ; 2009$.

[2] Kim SE, Song SH, Yun YP, Choi BJ, Kwon IK, Bae MS, Moon HJ and Kwon YD. The effect of immobilization of heparin and bone morphogenic protein-2 (BMP-2) to titanium surfaces on inflammation and osteoblast function. Biomaterrials, 32(2):366-73, 2011

[3] Shimono K, Oshima M, Arakawa H, Kimura A, Nawachi K and Kuboki $\mathrm{T}$. The effect of growth factors for bone augmentation to enable dental implant placement: A systematic review. The Japanese Dental Science Review, 46 (1): 43- 53, 2010 .

[4] Moioli EK, Clark PA, Xin X, Lal S, Jeremy J and Mao JJ. Matrices and scaffolds for drug delivery in dental, oral and craniofacial tissue engineering. Advanced Drug Delivery Reviews, 59 (4-5): 308-324, 2007.

[5] Yun KD, Yang Y, Lim HP, Oh GJ, Koh JT, Bae IH, Kim J, Lee KM and Park SW. Effect of nanotubular-micro-roughened titanium surface on cell response in vitro and osseointegration in vivo. Mater Sci and Engin C., 30 (1): 27-33, 2010.

[6] Lee YH, Bhattarai G, Aryal S, Lee NH, Lee MH L, Kim TG, Jhee EC, Kim HY and Yi HK. Modified titanium surface with gelatin nano gold composite increases osteoblast cell biocompatibility. Applied Surface Science, 256 (20): 5882-7, 2010 .

[7] Gultepe E, Nagesha D, Sridhar S and Amiji M. Nanoporous inorganic membranes or coatings for sustained drug delivery in implantable devices. Advanced drug delivery reviews, 62 (3): 305-15, 2010. Edited By P. Mukherjee

[8] Popat KC, Eltgroth M, LaTempa TJ, Grimes CA, Desai TA. Titania nanotubes: a novel platform for drug-eluting coatings for medical implants? Small, 3(11):1878-81, 2007.

[9] Drago L, Boot W, Dimas K, Malizos K , Hänsch GM, Stuyck J, Gawlitta D, Romano` CL. Does implant coating with antibacterial-loaded hydrogel reduce bacterial colonization and biofilm formation in vitro? Clin Orthop Relat Res, 472:3311-3323, 2014

[10] Meani E, Fini M, Giavaresi G , Drago L , Romanò CL. Antibacterial resorbable coating of orthopaedic implants: an in vitro and in vivo study. Bone joint 96-B Suppl 11:284, 2014

[11] Shalaby HA, Hashem AM, Badr NA, Shoeib MM and Khafagy MG. Preparation of ordered nano-titania arrays and electrodeposition of nano-hydroxyapatite crystals on Ti-6\%Al-4\%V dental implant surfaces. J American Science, 7 (4): 574-84, 2011

[12] Sumner DR, Turner TM, Urban RM, Virdi AS and Inoue N. Additive enhancement of implant fixation following combined treatment with rhTGF- $\beta 2$ and rhBMP-2 in a canine model. J Bone Joint Surg Am, 88 (4):806-817, 2006.

[13] Bauer S, Schmuki P, von der Mark K and Park J. Engineering Biocompatible Implant Surfaces: Part I: Materials and surfaces. Progress in Materials Science, 58 (3):261-326, 2013.

[14] Subramanian K, Tran D and Nguyen K T. Emerging Nanotechnologies in Dentistry: Processes, Materials and Applications (A volume in Micro and Nano Technologies)
ISBN: 978-1-4557-7862-1.Chapter 8: Cellular Responses to Nanoscale Surface Modifications of Titanium Implants for Dentistry and Bone Tissue Engineering Applications, 113-136, 2012

[15] Mendonça G, Mendonça DB, Aragão FJ and Cooper LF. Review: Advancing dental implant surface technology: From micron to nanotopography. Biomateriales, 29(28): 3822-35, 2008.

[16] Hu Y, Cai K, Luo Z, Xu D, Xie D, Huang Y, Yang W, Liu P. $\mathrm{TiO}_{2}$ nanotubes as drug nanoreservoirs for the regulation of mobility and differentiation of mesenchymal stem cells. Acta Biomater, 8 (1): 439-48, 2012.

[17] Vasilev K, Poh Z, Kant K, Chan J, Michelmore A and Losic D. Tailoring the surface functionalities of titania nanotube arrays. Biomaterials, 31 (3): 532-40, 2010.

[18] Biondi M, Ungaro F, Quaglia F and Netti P A. Controlled drug delivery in tissue engineering. Advanced Drug Delivery Reviews, 60 (2): 229-42, .2008.

[19] Signoretto M, Ghedini E, Nichele V, Pinna F, Crocellà V and Cerrato G. Effect of textural properties on the drug delivery behaviour of nanoporous $\mathrm{TiO}_{2}$ matrices. J Microporous and Mesoporous Materials, 139 (1-3): 189-96, 2011.

[20] Liu X, Paul K Chu PK and Ding C. Surface nano-functionalization of biomaterials. Materials Science and Engineering, 70 (3): 275-302, 2010.

[21] Le Guéhennec L, Soueidan A, Layrolle P and Amouriq Y. Review: Surface treatments of titanium dental implants for rapid osseointegration. Dental materials, 23 (7): 844-54, 2007.

[22] $\mathrm{Ku} \mathrm{CH}{ }^{1}$, Pioletti DP, Browne M, Gregson PJ. Effect of different Ti-6Al-4V surface treatments on osteoblasts behavior. Biomaterials, 23 (6): 1447-54, 2002.

[23] Li Y ${ }^{1}$, Gao Y, Shao B, Xiao J, Hu K, Kong L. Effects of hydrofluoric acid and anodised micro and micro/nano surface implants on early osseointegration in rats. Br J Oral Maxillofac Surg, 50 (8): 779-83, 2012.

[24] Li Y ${ }^{1}$, Zou S, Wang D, Feng G, Bao C, Hu J. The effect of hydrofluoric acid treatment on titanium implant osseointegration in ovariectomized rats. Biomaterials, 31 (12):3266-73, 2010.

[25] Krasicka-Cydzik E. Tailoring of anodic surface layer properties on titanium and its implant alloys for biomedical purposes. J Achievement in Materials and Manufacturing Engineering, 43 (1): 424-31, 2010.

[26] Anitha VC, Deepthy M, Nair SV and Prasanth R. Electrochemical tuning of titania nanotube morphology in inhibitor electrolytes. Electrochimica Acta, 55 (11): 3703-13, 2010 .

[27] Zhao J, Wang X, Chen R and Li L. Fabrication of titanium oxide nanotube arrays by anodic oxidation. Solid State Communications, 134 (10):705-10, 2005.

[28] Drnovšek N, Rade K, Milačič R, Štrancar J and Novak S. The properties of bioactive $\mathrm{TiO}_{2}$ coatings on Ti-based implants. Surface and Coatings Technology, 209:177-83, 2012.

[29] Slepička P, Siegel J, Kolska Z, Hnatowicz V and Švorčik V. 
Different microscopy approach for solid surface characterization. Microscopy: Science, Technology, Applications and Education, 1483-94, 2010.

[30] Flores CY, Diaz C, Rubert A, Benitez GA, Moreno MS, Fernandez de Mele MA, Salvarezza RC, Schilardi PL and Vericat C. Spontaneous adsorption of silver nanoparticles on $\mathrm{Ti} / \mathrm{TiO}_{2}$ surfaces. Antibacterial effect on Pseudomonas aeruginosa. J Colloid and Interface Science, 350 (2): 402-8, 2010.

[31] Nelson JM, Chiller TM, Powers JH and Angulo FJ. Fluoroquinolone-resistant Campylobacter species and the withdrawal of fluoroquinolones from use in poultry: a public health success story. Clin Infect Dis, 44 (7): 977-80, 2007.

[32] Robinson MJ, Martin BA, Gootz TD, McGuirk PR and Osheroff $\mathrm{N}$. Effects of novel fluoroquinolones on the catalytic activities of eukaryotic topoisomerase II: Influence of the C-8 fluorine group. Antimicrob. Agents Chemother, 36 (4): 751-6, 1992.
[33] Sarker SK, Mondal D and Siddique MA. Study of sensitivity pattern of Metronidazole on axenic culture of Entamoeba Histolytica in vitro. J Dhaka Med Coll, 19 (1):65-66, 2010.

[34] Ayon AA, Cantu M, Chava K, Agrawal CM, Feldman MD, Johnson D, Patel D, Marton D, Shi E. Drug loading of nanoporous $\mathrm{TiO}_{2}$ films, Biomed Mater, 1(4):L11-15, 2006.

[35] Hoang Thi TH, Chai F, Leprêtre S, Blanchemain N, Martel B, Siepmann F, Hildebrand HF, Siepmann J and Flament MP. Bone implants modified with cyclodextrin: Study of drug release in bulk fluid and into agarose gel. Int J Pharm, 400 (1-2): 74-85, 2010.

[36] Bose S and Tarafder S. Calcium phosphate ceramic systems in growth factor and drug delivery for bone tissue engineering: a review. Acta Biomater, 8 (4): 1401-21, 2012.

[37] Zhu Y and Kaskel S. Comparison of the in vitro bioactivity and drug release property of mesoporous bioactive glasses (MBGs) and bioactive glasses (BGs) scaffolds. Microporous and Mesoporous Materials, 118 (1-3):176-82, 2009. 